\title{
Enhanced fluoride adsorption using Al (III) modified calcium hydroxyapatite
}

\author{
Yulun Nie, Chun $\mathrm{Hu}^{*}$, Chuipeng Kong \\ State Key Laboratory of Environmental Aquatic Chemistry, Research Center for Eco-Environmental Sciences, Chinese Academy of Sciences, Beijing, 100085, China
}

\section{H I G H L I G H T S}

- Al modified hydroxyapatite possessed a higher defluoridation capacity of $32.57 \mathrm{mg} / \mathrm{g}$.

- Hydroxyl groups on the surface of Al-HAP was the adsorption sites for $\mathrm{F}^{-}$removal.

- Enhanced $\mathrm{F}^{-}$removal over Al-HAP was attributed to the modification with aluminum.

\section{A R T I C L E I N F O}

\section{Article history:}

Received 28 February 2012

Received in revised form 16 May 2012

Accepted 4 July 2012

Available online 13 July 2012

\section{Keywords:}

Hydroxyapatite

Aluminum

Fluoride

Adsorption

Removal

\begin{abstract}
A B S T R A C T
Aluminum-modified hydroxyapatite (Al-HAP) was prepared and characterized using XRD and BET analyses. Al-HAP possessed higher defluoridation capacity (DC) of $32.57 \mathrm{mgF}^{-} / \mathrm{g}$ than unmodified hydroxyapatite (HAP) which showed a DC of $16.38 \mathrm{mgF}^{-} / \mathrm{g}$. The effect of $\mathrm{Al} / \mathrm{Ca}$ atomic ratio in $\mathrm{Al}-\mathrm{HAP}$, solution $\mathrm{pH}$ and co-existing anions was further studied. The results indicated that the adsorption data could be well described by the Langmuir isotherm model and the adsorption kinetic followed the pseudo-second-order model. The $\mathrm{pH}$ changes during the adsorption process suggested that the $-\mathrm{OH}$ on the surface of Al-HAP was the adsorption sites. The more adsorption sites were formed on Al modified HAP, which possessed abundant surface hydroxyl groups, resulting in higher efficiency of $\mathrm{F}^{-}$removal. Thermodynamic parameters such as $\Delta G^{\circ}, \Delta H^{\circ}$ and $\Delta S^{\circ}$ were calculated in order to understand the nature of adsorption process. The results revealed that the adsorption reaction was a spontaneous and endothermic process.
\end{abstract}

(c) 2012 Elsevier B.V. All rights reserved.

\section{Introduction}

Presence of fluoride in drinking water can be beneficial or harmful depending on its concentration [1]. Excess ingestion of fluoride with high concentration can induce mottling of teeth, softening of bones, even neurological damages [2]. So, fluorosis is an important public health problem all over the world, and an appropriate concentration of fluoride $(0.5-1.5 \mathrm{mg} / \mathrm{L})$ is required to prevent dental cavities [3-5].

Fluoride removal from drinking water could be achieved by chemical precipitation, adsorption, membrane and ion exchange [6]. Among these methods, membrane and ion exchange processes are not very common due to its high installation and maintenance cost, while chemical precipitation results in relatively higher residual fluoride concentration in the effluents [5,7]. Adsorption process is a widely accepted technique because of its ease of operation and cost-effectiveness [3]. Activated alumina is one of the most economical adsorbent for fluoride removal from drinking water. However, the slow rate of adsorption of commercially available

\footnotetext{
* Corresponding author. Tel.: +86 10 62849628; fax: +861062923541.

E-mail address: huchun@rcees.ac.cn (C. Hu).
}

activated alumina limits its use for treating large quantity of water $[8,9]$. In recent years, many efforts have been devoted to investigate and develop new fluoride adsorbent using various synthetic, naturally occurring and waste materials, such as fly ash [10], clay [11], hydrotalcite [12], zeolite [13], etc.

Hydroxyapatite (HAP) is a calcium phosphate based bioceramic and used in the medical field as it is the main component of the hard tissues of living bodies such as bones, teeth, etc. [14]. It has been proven that nanoscale materials offer new possibilities to chemists and the surface properties, electronic structure, coordination etc. would be modified when material dimensions reach the nanoscale [1]. Nano-HAP was hence used as adsorbent material to remove fluoride from water and exhibited high performance for fluoride removal $[1,15,16]$. It has been reported that the surface hydroxyl groups are the active site for adsorbent material and the heavy metals removing by adsorption depends on the surface site $[1,17]$. Therefore, the fluoride removal efficiency should be greatly enhanced by increasing the amount of surface hydroxyl groups on the Nano-HAP.

In this paper, aluminum modified calcium hydroxyapatite (AlHAP) nanoparticles were synthesized by co-precipitation method and defluoridation studies were carried out under various conditions such as the effect of $\mathrm{Al} / \mathrm{Ca}$ atomic ratio in $\mathrm{Al}-\mathrm{HAP}$, solution $\mathrm{pH}$ 
and competitor anions. The results indicated that Al-HAP possessed higher defluoridation capacity (DC) of $32.57 \mathrm{mgF}^{-} / \mathrm{g}$ than unmodified hydroxyapatite (HAP) which showed a DC of $16.38 \mathrm{mgF}^{-} / \mathrm{g}$. Moreover, the experimental data were fitted with isotherms and the kinetic models. The equilibrium and kinetic studies would definitely throw more light in understanding the defluoridation mechanism of Al-HAP. Moreover, the reasonable mechanism of fluoride removal by Al-HAP was also suggested.

\section{Materials and methods}

\subsection{Materials}

$\mathrm{Ca}\left(\mathrm{NO}_{3}\right)_{2} \cdot 4 \mathrm{H}_{2} \mathrm{O}, \mathrm{Al}\left(\mathrm{NO}_{3}\right)_{3} \cdot 9 \mathrm{H}_{2} \mathrm{O}, \mathrm{H}_{3} \mathrm{PO}_{4}$ and $\mathrm{NH}_{4} \mathrm{OH}$ were purchased from the YiLi Company. $\mathrm{NaF}, \mathrm{NaOH}, \mathrm{HCl}$ and all other chemicals and reagents were all analytical grade and used as received without purification. The fluoride stock solution was prepared with deionized water using NaF. Fluoride working solutions were freshly prepared by diluting fluoride stock solution with deionized water. Deionized and doubly distilled water was used throughout this study. $\mathrm{NaOH}$ and $\mathrm{HCl}$ solutions were used to adjust the $\mathrm{pH}$ of the solution.

\subsection{Adsorbent preparation}

Al modified HAP particles were prepared by co-precipitation method. $\mathrm{Ca}\left(\mathrm{NO}_{3}\right)_{2}$ and $\mathrm{Al}\left(\mathrm{NO}_{3}\right)_{3}$ were dissolved in $1 \mathrm{~L}$ deionizeddistilled water free from $\mathrm{CO}_{2}$ at atomic ratios $\mathrm{Al} / \mathrm{Ca}$ from 0 to 0.5 . The total amount of $\mathrm{Ca}$ and $\mathrm{Al}$ in solution was held at $0.1 \mathrm{~mol} .0 .06 \mathrm{~mol}$ of $\mathrm{H}_{3} \mathrm{PO}_{4}$ was added to the solutions and the solution $\mathrm{pH}$ was adjusted to 9 by adding a $15 \mathrm{M} \mathrm{NH}_{4} \mathrm{OH}$ solution. The suspension was aged in a capped Teflon vessel at $100^{\circ} \mathrm{C}$ for $6 \mathrm{~h}$. The resulting precipitates were filtered off, washed with $5 \mathrm{~L}$ deionized-distilled water, and finally dried at $70^{\circ} \mathrm{C}$ overnight in air.

As a reference, HAP particles were synthesized by the same process.

\subsection{Characterization of adsorbents}

Powder X-ray diffraction of the adsorbents were recorded on a Scintag-XDS-2000 diffractometer with $\mathrm{Cu} \mathrm{K \alpha}$ radiation $(\lambda=1.54059 \AA)$. Nitrogen adsorption/desorption experiments were carried out using a Micromeritics ASAP2000 analyzer (Micromeritics Co., USA). TEM images of the catalyst were examined using a TEM Hitachi H-7500. The infrared spectra were recorded on Bruker Tensor 27 FTIR Spectrophotometer. The $\mathrm{KBr}$ pellet technique was used and the spectra data was recorded from 4000 to $400 \mathrm{~cm}^{-1}$ with a resolution of $4 \mathrm{~cm}^{-1}$. The Zeta potential of the absorbents in the $\mathrm{KNO}_{3}\left(10^{-3} \mathrm{M}\right)$ solution was measured with a Zetasizer 2000 (Malvern, Worcestershire, UK) with three consistent readings.

\subsection{Adsorption experiments}

Stock solution of sodium fluoride containing $100 \mathrm{mg} / \mathrm{L}$ was prepared and this was used for fluoride sorption experiments. All batch fluoride adsorption studies were carried out in $250 \mathrm{~mL}$ Teflon flasks with a working volume of $100 \mathrm{ml}$. After adding the required amount of Al-HAP $(0.5 \mathrm{~g} / \mathrm{L})$ to the fluoride solution $(10 \mathrm{mg} / \mathrm{L})$, the flasks were sealed and kept in an orbital shaker with thermostatic control at $180 \mathrm{rpm}$ and $25^{\circ} \mathrm{C}$ for specified contact time. The solution at predetermined time intervals was filtered and the residual fluoride concentration was measured. The fluoride concentration in solutions was determined using expandable ion analyzer (Rex, PHS-3C) and the fluoride ion selective electrode pF-1.

The kinetic and thermodynamic parameters of the adsorption were established by conducting the experiments at 288, 298 and

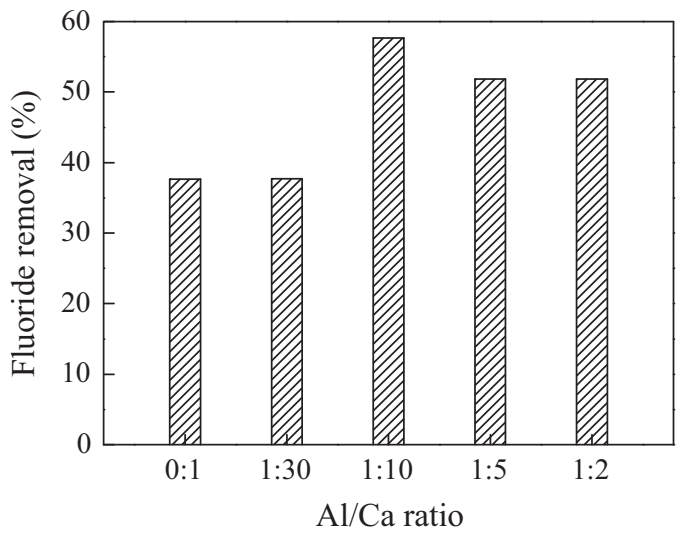

Fig. 1. Fluoride removal onto $\mathrm{Al}-\mathrm{HAP}$ with different $\mathrm{Al} / \mathrm{Ca}$ atomic ratio (adsorbent, $\left.0.5 \mathrm{~g} / \mathrm{L} ;\left[\mathrm{F}^{-}\right]_{0}=10 \mathrm{mg} / \mathrm{L} ; \mathrm{pH}=7.0\right)$.

$308 \mathrm{~K}$ in a temperature controlled mechanical shaker. Moreover, the defluoridation capacity was studied at different conditions like $\mathrm{Al}-\mathrm{HAP}$ with different $\mathrm{Al} / \mathrm{Ca}$ atomic ratio, contact time, $\mathrm{pH}$ of the medium and the effect of co-anions on defluoridation. Adsorption isotherms were obtained in batch equilibrium experiments with $0.05 \mathrm{~g}$ of HAP or Al-HAP in $100 \mathrm{ml}$ solutions of fluoride (concentrations up to $50 \mathrm{mg} / \mathrm{L}$ at $\mathrm{pH}=7.0, T=25^{\circ} \mathrm{C}$ ).

\section{Results and discussion}

\subsection{Selection and characterization of Al-HAP adsorbent}

The effect of Al doping dose on the adsorption capacity of hydroxyapatite was evaluated by the fluoride removal and the results were shown in Fig. 1. Obviously, the sample with the ratio of Al to Ca 1:10 exhibited the highest efficiency for the removal of fluoride, which was then used for all the adsorption experiments (Al-HAP) unless otherwise specified.

Fig. 2 showed the X-ray diffraction patterns of Al-HAP with different $\mathrm{Al} / \mathrm{Ca}$ atomic ratio. In comparison with the characteristic patterns of HAP (curve a), Al-HAP (1:10) had almost identical XRD patterns to that of pure HAP (curve $b$ ). There was a good match with standard both in terms of intensity and position of the peaks. The crystalline peaks at $2 \theta=26^{\circ}, 32^{\circ}, 40^{\circ}, 47^{\circ}$ and $50^{\circ}$ confirmed the formation of hydroxyapatite structure. No peaks that correspond to $\mathrm{Al}$ element were found. This may be due to the $\mathrm{Al}$ (III) incorporation into hydroxyapatite. While the main crystalline phase of HAP disappeared in 1:5 and 1:2 samples (curve $c$ and $d$ ), indicating the higher Al doping dose did not favor the formation of HAP structure.

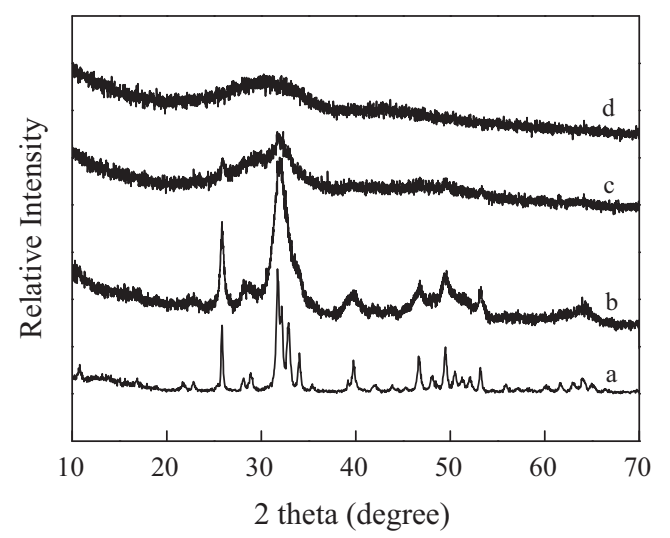

Fig. 2. XRD patterns of Al-HAP with different Al/Ca atomic ratio: (a) 0, (b) 1:10, (c) $1: 5$, (d) $1: 2$. 

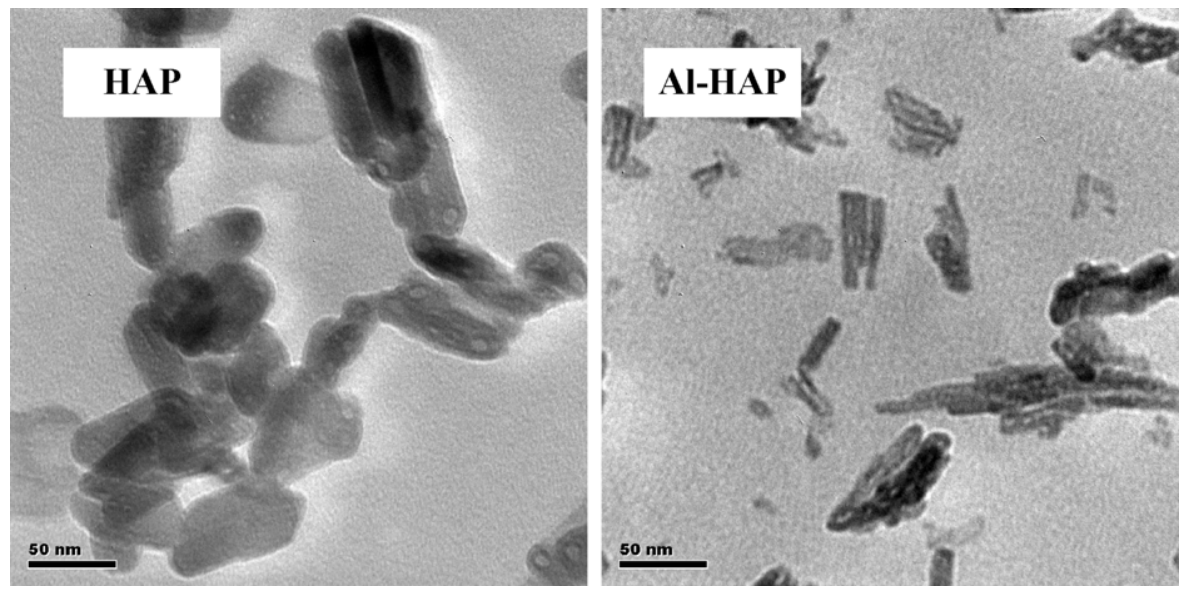

Fig. 3. TEM images of HAP and Al-HAP.

Moreover, the size and shape of HAP and Al-HAP was measured by TEM (Fig. 3). The HAP samples were cylindrical rod-like shape with homogeneous microstructure, $25-30 \mathrm{~nm}$ in diameter and $50-80 \mathrm{~nm}$ in length and several particles seem to aggregate together by melting their surfaces. However, the particle sizes of Al-HAP (5-15 $\mathrm{nm}$ in diameter and $20-50 \mathrm{~nm}$ in length) decreased significantly with the presence of $\mathrm{Al}$ element. In comparison with HAP, Al-HAP was more dispersible and fluffy, resulting in high defluoridation capacity.

Fig. 4 presented the nitrogen adsorption-desorption isotherms of different samples. Both the isotherms were the type IV with hysteresis loops in different sizes. Al-HAP had a surface area of $258.6 \mathrm{~m}^{2} / \mathrm{g}$, which was almost 4 times larger than that of HAP $\left(75.7 \mathrm{~m}^{2} / \mathrm{g}\right)$. This result also agreed well with the TEM analysis.

\subsection{Adsorption kinetics and the effects of $\mathrm{pH}$ and co-existing anions on fluoride removal}

The kinetics of adsorption is an important parameter for designing adsorption system and is required for selecting optimum operating conditions for full-scale batch process. Fig. 5 illustrated the kinetics of fluoride adsorption onto Al-HAP as a function of reaction time. Obviously, most of the removal took place during the first $5 \mathrm{~h}$. From the shape of the kinetic curve, it was evident that the fluoride adsorption onto Al-HAP is a two-step process, i.e. initial rapid adsorption during the first $5 \mathrm{~h}$ and slow rate of adsorption until the equilibrium was reached. The kinetics of any sorption process is a function of different parameters, such as the structural properties of adsorbent, nature and concentration of sorbate, and

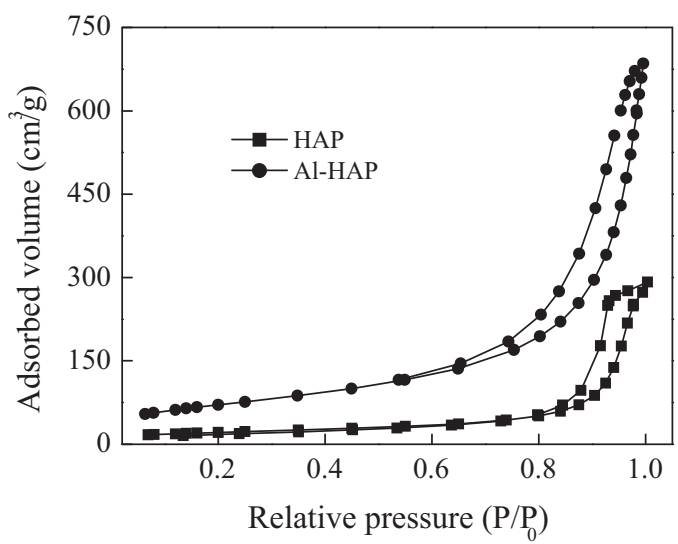

Fig. 4. Nitrogen adsorption-desorption isotherms of HAP and Al-HAP. adsorbent-sorbate interactions. The results indicated that nonlinear method is more suitable to obtain the kinetic parameters. In our study, the kinetic data fitted well with pseudo-second-order equation.

$\frac{\mathrm{d} q_{\mathrm{t}}}{\mathrm{d} t}=k_{2}\left(q_{\mathrm{e}}-q_{\mathrm{t}}\right)^{2} \rightarrow \frac{t}{q_{\mathrm{t}}}=\frac{1}{k_{2} q_{\mathrm{e}}^{2}}+\frac{t}{q_{\mathrm{e}}}$

where $q_{\mathrm{t}}$ is the amount of fluoride on the surface of Al-HAP at any time $(\mathrm{mg} / \mathrm{g}), k_{2}$ is the pseudo-second-order rate constant ( $\mathrm{g} / \mathrm{mg} \min ), q_{\mathrm{e}}$ is the amount fluoride adsorbed at equilibrium $(\mathrm{mg} / \mathrm{g})$ and the initial adsorption rate.

The $\mathrm{pH}$ of the medium is one of the important variables which significantly affect the extent of adsorption of fluoride. Fig. 6 showed the effect of the initial solution $\mathrm{pH}$ on the fluoride adsorption onto Al-HAP at given conditions. Obviously, the maximum fluoride removal $(75 \%)$ was recorded at $\mathrm{pH}=5.0$ and showed gradual decreasing trend with increase in the solution $\mathrm{pH}$. This was in agreement with fluoride removal studies on synthetic HAP by other report $[1,18]$. The reduction of fluoride removal in alkaline $\mathrm{pH}$ range should be attributed to competition of hydroxyl ions with fluoride for adsorption sites because of similarity in fluoride and hydroxyl ions in charge and ionic radius. Similar findings have also been reported earlier $[19,20]$.

Moreover, the concentration of $\mathrm{Ca}^{2+}$ and $\mathrm{Al}^{3+}$ in solution after the adsorption experiments at different $\mathrm{pH}$ was measured using ICP-AES to confirm the degree of dissolution of $\mathrm{Ca}^{2+}$ and $\mathrm{Al}^{3+}$ from Al-HAP. From the results in Fig. 7, the maximum amount of $\mathrm{Ca}^{2+}$ and $\mathrm{Al}^{3+}$ was 21.1 and $0.19 \mathrm{mg} / \mathrm{L}$ at $\mathrm{pH}=5.0$, while Al-HAP was insoluble

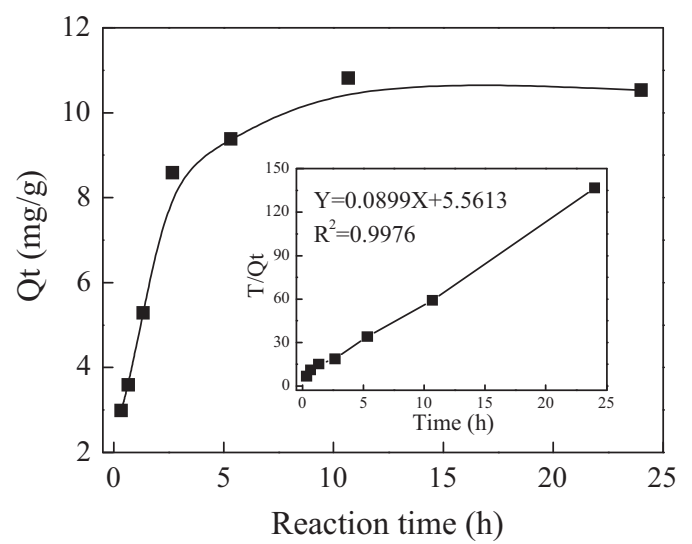

Fig. 5. Pseudo-second-order adsorption rate of $\mathrm{F}^{-}$adsorption onto Al-HAP (adsorbent, $\left.0.5 \mathrm{~g} / \mathrm{L} ;\left[\mathrm{F}^{-}\right]_{0}=10 \mathrm{mg} / \mathrm{L} ; \mathrm{pH}=7.0\right)$. 


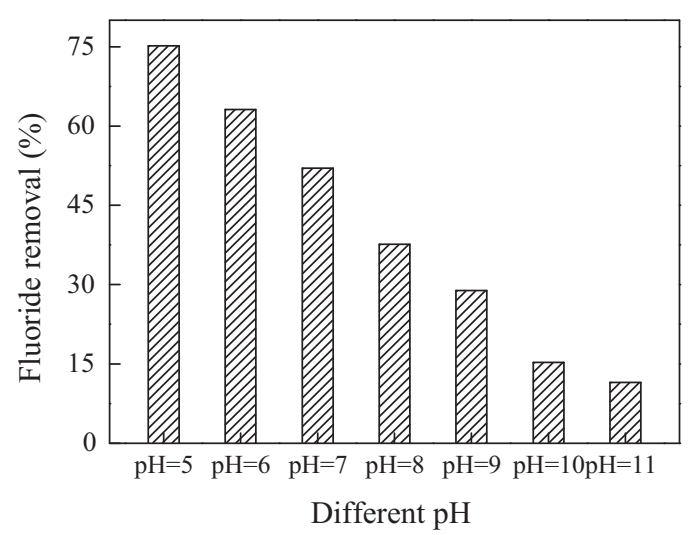

Fig. 6. Fluoride removal onto $\mathrm{Al}-\mathrm{HAP}$ at various initial $\mathrm{pH}$ values (adsorbent, $0.5 \mathrm{~g} / \mathrm{L}$; $\left.\left[\mathrm{F}^{-}\right]_{0}=10 \mathrm{mg} / \mathrm{L}\right)$.

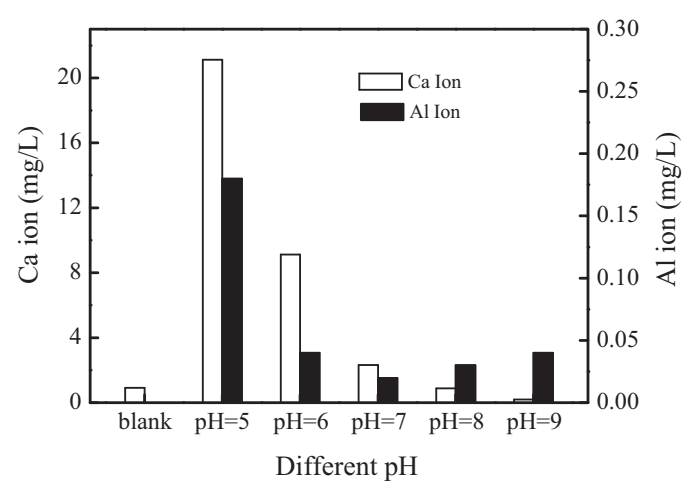

Fig. 7. $\mathrm{Ca}^{2+}$ and $\mathrm{Al}^{3+}$ dissolution from $\mathrm{Al}-\mathrm{HAP}$ at various initial $\mathrm{pH}$ values (adsorbent, $\left.0.5 \mathrm{~g} / \mathrm{L} ;\left[\mathrm{F}^{-}\right]_{0}=10 \mathrm{mg} / \mathrm{L}\right)$.

or dissolved the least in the initial pH of 7-9. This indicated that Al$\mathrm{HAP}$ in the $\mathrm{pH}$ range was stable enough and was appropriate for use as a fluoride adsorbent.

The contaminated ground water contains several other coexisting ions along with fluoride, which may compete with fluoride for the active adsorption sites. Hence, it is important to investigate the interference of co-existing ions of fluoride adsorption onto $\mathrm{Al}$ HAP. Fig. 8 showed the effect of various co-existing ions of different concentrations on fluoride adsorption by Al-HAP. Except $\mathrm{CO}_{3}{ }^{2-}$ and $\mathrm{PO}_{4}{ }^{3-}, \mathrm{Cl}^{-}, \mathrm{NO}_{3}{ }^{-}$and $\mathrm{SO}_{4}{ }^{2-}$ have shown negligible effect on fluoride adsorption. Interference was observed on fluoride adsorption by $\mathrm{CO}_{3}{ }^{2-}$ and $\mathrm{PO}_{4}{ }^{3-}$ ions above a concentration of $0.2 \mathrm{mM}$. Fluoride

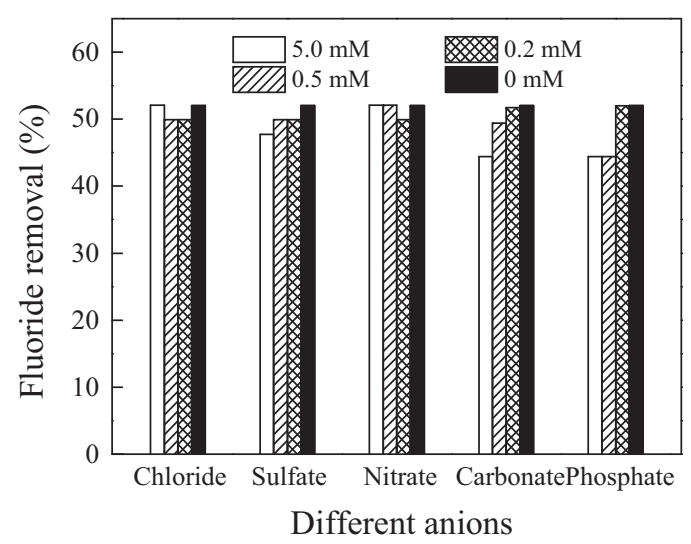

Fig. 8. Effect of co-existing anions on the $\mathrm{F}^{-}$adsorption onto Al-HAP (adsorbent, $\left.0.5 \mathrm{~g} / \mathrm{L} ;\left[\mathrm{F}^{-}\right]_{0}=10 \mathrm{mg} / \mathrm{L} ; \mathrm{pH}=7.0\right)$.
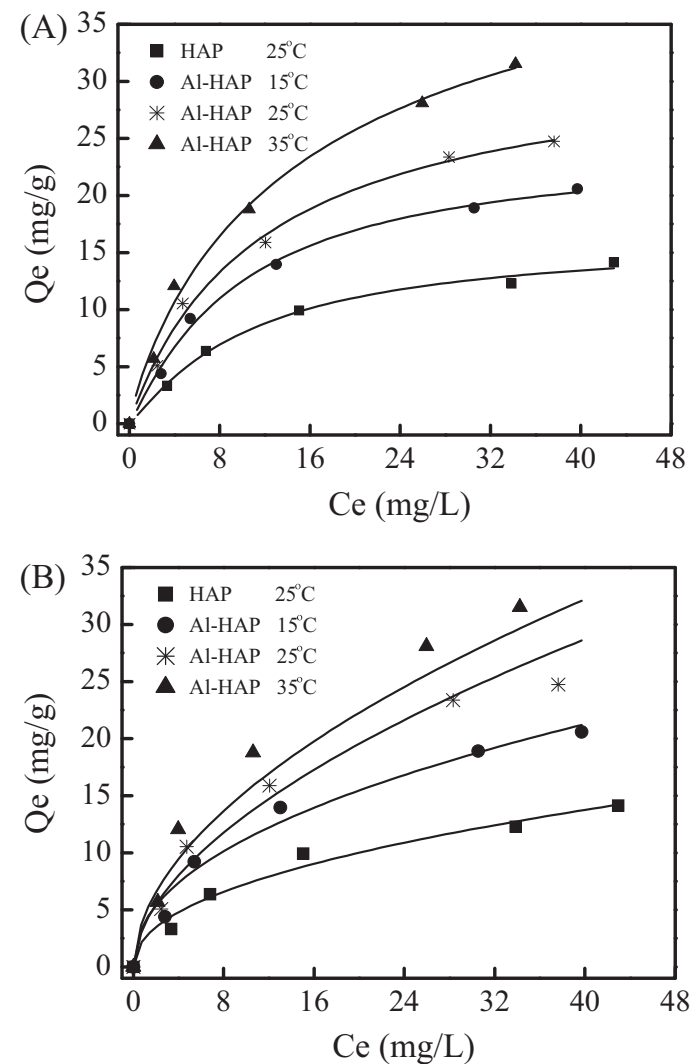

Fig. 9. Langmuir (A) and Freundlich (B) isotherms for $\mathrm{F}^{-}$adsorption by Al-HAP (adsorbent, $0.5 \mathrm{~g} / \mathrm{L} ;\left[\mathrm{F}^{-}\right]_{0}=5-50 \mathrm{mg} / \mathrm{L} ; \mathrm{pH}=7.0$ ).

adsorption capacity was reduced by $10 \%$ for an initial $\mathrm{CO}_{3}{ }^{2-}$ and $\mathrm{PO}_{4}{ }^{3-}$ concentration of $5 \mathrm{mM}$. The reduction in fluoride removal observed by the presence of $\mathrm{CO}_{3}{ }^{2-}$ and $\mathrm{PO}_{4}{ }^{3-}$ may be due to competition from these ions for active site $[1,3,7]$.

\subsection{Adsorption isotherm and the mechanism of fluoride removal over Al-HAP}

Analysis of equilibrium data is important for developing an equation that can be used to compare different adsorbents under different operational conditions and to design and optimize an operating procedure. The adsorption isotherms of HAP and Al-HAP were shown in Fig. 9. Data from the adsorption isotherms were modeled using the Langmuir and Freundlich isotherm models with the resulting isotherm constants presented in Table 1.

$\frac{C_{\mathrm{e}}}{q_{\mathrm{e}}}=\frac{1}{\mathrm{Q}_{\max } b}+\frac{C_{\mathrm{e}}}{\mathrm{Q}_{\max }}$ Langmuir model

$\log q_{\mathrm{e}}=\log K_{\mathrm{F}}+\frac{1}{n} \log C_{\mathrm{e}}$ Freundich modelwhere $C_{\mathrm{e}}$ is equilibrium concentration $(\mathrm{mg} / \mathrm{L}), q_{\mathrm{e}}$ is the amount adsorbed at equilibrium ( $\mathrm{mg} / \mathrm{g}), Q_{\max }$ is adsorption capacity for Langmuir isotherms and ' $b$ ' is an energy term which varies as a function of surface coverage strictly due to variations in the heat of adsorption. ' $n$ ' indicates the degree of favorability of adsorption and $K_{\mathrm{F}}$ is the isotherm constant for Freundich model.

As seen in Fig. 9, Table 1 and S1, fluoride adsorption onto HAP and Al-HAP was well described by the Langmuir model with the correlation coefficients of $R^{2}>0.99$. The calculated maximum adsorption capacity $Q_{\max }$ for Al-HAP was $32.57 \mathrm{mg} / \mathrm{L}$ at $25^{\circ} \mathrm{C}$, which was twice larger than that of HAP $(16.38 \mathrm{mg} / \mathrm{L})$. Results from the Freundich analysis indicated that the standard deviation was significantly higher than the Langmuir analysis in describing the adsorption of fluoride onto the HAP and Al-HAP. The fact that the Langmuir isotherm fitted the experimental data very well 
Table 1

Langmuir and Freundlich isotherm constants for $\mathrm{F}^{-}$adsorption by Al-HAP and HAP.

\begin{tabular}{|c|c|c|c|c|c|c|c|}
\hline \multirow[t]{2}{*}{ Adsorbent } & \multirow[t]{2}{*}{ Temperature } & \multicolumn{3}{|c|}{ Langmuir model } & \multicolumn{3}{|c|}{ Freundlich model } \\
\hline & & $Q_{\max }(\mathrm{mg} / \mathrm{g})$ & $b\left(1 g^{-1}\right)$ & $R^{2}$ & $K_{\mathrm{F}}\left(1 \mathrm{~g}^{-1}\right)$ & $n$ & $R^{2}$ \\
\hline \multirow[t]{2}{*}{ HAP } & $25^{\circ} \mathrm{C}$ & 16.38 & 0.0688 & 0.9898 & 2.528 & 2.178 & 0.9810 \\
\hline & $15^{\circ} \mathrm{C}$ & 26.95 & 0.0800 & 0.9914 & 3.884 & 2.169 & 0.9815 \\
\hline \multirow[t]{2}{*}{ Al-HAP } & $25^{\circ} \mathrm{C}$ & 32.57 & 0.0859 & 0.9917 & 3.690 & 1.813 & 0.9846 \\
\hline & $35^{\circ} \mathrm{C}$ & 42.37 & 0.0802 & 0.9875 & 4.504 & 1.875 & 0.9908 \\
\hline
\end{tabular}

Table 2

Thermodynamic parameters for $\mathrm{F}^{-}$removal on Al-HAP.

\begin{tabular}{lrrr}
\hline Temperature & $15^{\circ} \mathrm{C}$ & $25^{\circ} \mathrm{C}$ & $35^{\circ} \mathrm{C}$ \\
\hline$\Delta G^{\circ}(\mathrm{kJ} / \mathrm{mol})$ & -1.279 & -1.586 & -2.842 \\
$\ln K_{\mathrm{C}}$ & 0.232 & 0.278 & 0.482 \\
\hline
\end{tabular}

$\Delta H^{\circ}: 18.1 \mathrm{~kJ} / \mathrm{mol}, \Delta S^{\circ}: 67.2 \mathrm{~J} / \mathrm{mol} \mathrm{K}$.

may be due to homogeneous distribution of active sites on the adsorbents surface and the adsorption of fluoride took place in a monolayer adsorption manner [21]. Furthermore, as the temperature increased from 15 to $35^{\circ} \mathrm{C}$, a positive effect was observed on the adsorption of fluoride (Table 1 ). This phenomenon was because of the increased tendency of fluoride attached to Al-HAP, which might also indicated that the adsorption of fluoride onto Al-HAP was endothermic in nature. In order to study the feasibility of the process, the thermodynamic parameters were obtained from the following equations:

$K_{\mathrm{C}}=\frac{C_{\mathrm{Ae}}}{C_{\mathrm{e}}}$

$\Delta G^{0}=-R T \ln K_{\mathrm{C}}$

$\log K_{\mathrm{C}}=\frac{\Delta S^{0}}{2.303 R}-\frac{\Delta H^{0}}{2.303 T R}$

where $C_{\mathrm{e}}$ is the equilibrium concentration in solution in $\mathrm{mg} / \mathrm{L}$ and $C_{\mathrm{Ae}}$ is the equilibrium concentration on the adsorbent in $\mathrm{mg} / \mathrm{L}$ and $K_{\mathrm{C}}$ is the equilibrium constant.

The values of $\Delta H^{\circ}$ and $\Delta S^{\circ}$ can be obtained from the slope and intercept of a plot of $\ln K_{C}$ vs. $1 / T$ and the results were represented in Table 2. The adsorption of fluoride onto Al-HAP was endothermic in nature.

To further study the mechanism for fluoride adsorption to Al$\mathrm{HAP}$, the $\mathrm{pH}$ changes of Al-HAP suspension without/with fluoride was measured and the results were shown in Fig. 10. Apparently, the $\mathrm{pH}$ of Al-HAP suspension increased with the reaction time and

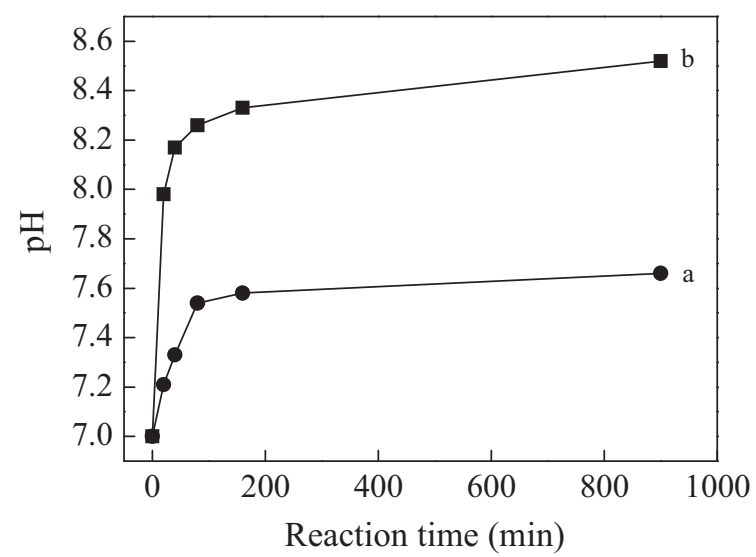

Fig. 10. The pH changes of Al-HAP suspension: (a) without $\mathrm{F}^{-}$, (b) with $\mathrm{F}^{-}$(adsorbent, $\left.0.5 \mathrm{~g} / \mathrm{L} ;\left[\mathrm{F}^{-}\right]_{0}=10 \mathrm{mg} / \mathrm{L} ; \mathrm{pH}=7.0\right)$. reached to 8.5 during the $\mathrm{F}^{-}$adsorption process. While the $\mathrm{pH}$ of suspension without $\mathrm{F}^{-}$was only 7.5. Moreover, Zeta potential and FTIR spectra (Fig. S1 and S2) of Al-HAP before and after $\mathrm{F}^{-}$adsorption were further investigated. Obviously, after the $\mathrm{F}^{-}$adsorption, the zeta potential of Al-HAP was greatly decreased and the $-\mathrm{OH}$ stretching vibrations at $3420 \mathrm{~cm}^{-1}$ also shifted to higher frequencies. The result indicated that the surface $\mathrm{M}-\mathrm{OH}$ was active sites and the quantitative substitution of the $\mathrm{M}-\mathrm{OH}$ groups by $\mathrm{F}^{-}$played a key role in $\mathrm{F}^{-}$adsorption.

\section{Conclusion}

Al-modified hydroxyapatite was prepared and used for the adsorption of $\mathrm{F}^{-}$from aqueous solution. It showed higher efficiency for the removal of $\mathrm{F}^{-}(32.57 \mathrm{mg} / \mathrm{g})$ than that of unmodified HAP $(16.38 \mathrm{mg} / \mathrm{g})$. The adsorption data could be well described by the Langmuir isotherm model and the adsorption kinetic followed the pseudo-second-order model. It has been suggested that the $-\mathrm{OH}$ on the surface of Al-HAP was the adsorption sites. The more adsorption sites were formed on Al modified HAP, which possessed abundant surface hydroxyl groups, resulting higher efficiency for $\mathrm{F}^{-}$removal.

\section{Acknowledgement}

This work was supported by the National Natural Science Foundation of China (Nos. 50921064, 50908223).

\section{Appendix A. Supplementary data}

Supplementary data associated with this article can be found, in the online version, at http://dx.doi.org/10.1016/j.jhazmat. 2012.07.020.

\section{References}

[1] C.S. Sundaram, N. Viswanathan, S. Meenakshi, Defluoridation chemistry of synthetic hydroxyapatite at nano scale: Equilibrium and kinetic studies, J. Hazard. Mater. 155 (2008) 206-215.

[2] S.X. Teng, S.G. Wang, W.X. Gong, X.W. Liu, B.Y. Gao, Removal of fluoride by hydrous manganese oxide-coated alumina-performance and mechanism, J. Hazard. Mater. 168 (2009) 1004-1011.

[3] N. Viswanathan, S. Meenakshi, Enhanced fluoride sorption using La (III) incorporated carboxylated chitosan beads, J. Colloid Interface Sci. 322 (2008) 375-383.

[4] M.G. Sujana, H.K. Pradhan, S. Anand, Studies on sorption of some geomaterials for fluoride removal from aqueous solutions, J. Hazard. Mater. 161 (2009) 120-125.

[5] M. Mohapatra, S. Anand, B.K. Mishra, D.E. Giles, P. Singh, Review of fluoride removal from drinking water, J. Environ. Manage. 91 (2009) 67-77.

[6] M.G. Sujana, G. Soma, N. Vasumathi, S. Anand, Studies on fluoride adsorption capacities of amorphous $\mathrm{Fe} / \mathrm{Al}$ mixed hydroxides from aqueous solutions, J. Fluorine Chem. 130 (2009) 749-754.

[7] S.M. Maliyekkal, S. Shukla, L. Philip, I.M. Nambi, Enhanced fluoride removal from drinking water by magnesia-amended activated alumina granules, Chem. Eng. J. 140 (2008) 183-192.

[8] Y.L. Tang, X.H. Guan, T.Z. Su, N.Y. Gao, J.M. Wang, Fluoride adsorption onto activated alumina: modeling the effects of $\mathrm{pH}$ and some competing ions, Colloids Surf., A 337 (2009) 33-38.

[9] N. Das, P. Pattanaik, R. Das, Defluoridation of drinking water using activated titanium rich bauxite, J. Colloid Interface Sci. 292 (2005) 1-10.

[10] A.K. Chaturvedi, K.P. Yadava, K.C. Pathak, V.N. Singh, Defluoridation of water by adsorption on fly ash, Water Air, Soil Pollut. 49 (1990) 51-61. 
[11] S. Meenakshi, C.S. Sundaram, R. Sukumar, Enhanced fluoride sorption by mechanochemically activated kaolinites, J. Hazard. Mater. 153 (2008) 164-172.

[12] H.T. Wang, J. Chen, Y.F. Cai, J.F. Ji, L.W. Liu, H.H. Teng, Defluoridation of drinking water by $\mathrm{Mg} / \mathrm{Al}$ hydrotalcite-like compounds and their calcined products, Appl. Clay Sci. 35 (2007) 59-66.

[13] M.S. Onyango, Y. Kojima, O. Aoyi, E.C. Bernardo, H. Matsuda, Adsorption equilibrium modeling and solution chemistry dependence of fluoride removal from water by trivalent-cation-exchanged zeolite F-9, J. Colloid Interface Sci. 279 (2004) 341-350.

[14] S.Q. Chen, Z.Q. Zhu, J.Z. Zhu, J. Zhang, Y.L. Shi, K. Yu, W.M. Wang, X.H. Wang, F. Xiao, L.Q. Luo, L. Shao, Hydroxyapatite coating on porous silicon substrate obtained by precipitation process, Appl. Surf. Sci. 230 (2004) 418-424.

[15] S. Gao, J. Cui, Z.G. Wei, Study on the fluoride adsorption of various apatite materials in aqueous solution, J. Fluorine Chem. 130 (2009) 1035-1041.

[16] C.S. Sundaram, N. Viswanathan, S. Meenakshi, Fluoride sorption by nanohydroxyapatite/chitin composite, J. Hazard. Mater. 172 (2009) 147-151.
[17] Y. Zhang, M. Yang, X.M. Dou, H. He, D.S. Wang, Arsenate adsorption on a Fe-Ce bimetal oxide adsorbent: role of surface properties, Environ. Sci. Technol. 39 (2005) 7246-7253.

[18] A. Bahdod, S.E. Asri, A. Saoiabi, T. Coradin, A. Laghzizil, Adsorption of phenol from an aqueous solution by selected apatite adsorbents: kinetic process and impact of the surface properties, Water Res. 43 (2009) 313-318.

[19] M.G. Sujana, R.S. Thakur, S.B. Rao, Removal of fluoride from aqueous solution by using alum sludge, J. Colloid Interface Sci. 206 (1998) 94-101.

[20] D.P. Das, J. Das, K. Parida, Physicochemical characterization and adsorption behavior of calcined $\mathrm{Zn} / \mathrm{Al}$ hydrotalcite-like compound (HTlc) towards removal of fluoride from aqueous solution, J. Colloid Interface Sci. 261 (2003) 213-220.

[21] G.S. Zhang, J.H. Qu, H.J. Liu, A.T. Cooper, R.C. Wu, $\mathrm{CuFe}_{2} \mathrm{O}_{4} /$ activated carbon composite: a novel magnetic adsorbent for the removal of acid orange II and catalytic regeneration, Chemosphere 68 (2007) 1058-1066. 